\title{
Postgraduate Mathematics Education Students' Perceptions of Technology-based Tools and Resources: Exploring the Influences of Connectivism and the Three Worlds of Mathematics
}

\author{
Jayaluxmi Naidoo ${ }^{1, *}$, Rajendran Govender ${ }^{2}$ \\ ${ }^{1}$ Mathematics and Computer Science Education Cluster, School of Education, College of Humanities, University of KwaZulu-Natal, \\ Durban, 4041, KwaZulu-Natal, South Africa \\ ${ }^{2}$ School of Science and Mathematics Education, Faculty of Education, University of Western Cape, Bellville, 7535, Cape Town, \\ South Africa
}

Received March 9, 2021; Revised March 29, 2021; Accepted May 23, 2021

\section{Cite This Paper in the following Citation Styles}

(a): [1] Jayaluxmi Naidoo, Rajendran Govender, "Postgraduate Mathematics Education Students' Perceptions of Technology-based Tools and Resources: Exploring the Influences of Connectivism and the Three Worlds of Mathematics," Universal Journal of Educational Research, Vol. 9, No. 6, pp. 1214-1223, 2021. DOI: 10.13189/ujer.2021.090610.

(b): Jayaluxmi Naidoo, Rajendran Govender (2021). Postgraduate Mathematics Education Students' Perceptions of Technology-based Tools and Resources: Exploring the Influences of Connectivism and the Three Worlds of Mathematics. Universal Journal of Educational Research, 9(6), 1214-1223. DOI: 10.13189/ujer.2021.090610.

Copyright $\bigcirc 2021$ by authors, all rights reserved. Authors agree that this article remains permanently open access under the terms of the Creative Commons Attribution License 4.0 International License

\begin{abstract}
As we embrace the Fourth Industrial Revolution, transformations in education necessitate the use of technology-based pedagogy. This study explored postgraduate mathematics education students' perceptions of using technology-based tools and resources. This qualitative and interpretive study was conducted at a university in KwaZulu-Natal, South Africa. The study was framed utilizing the theory of connectivism and the three worlds of mathematics theory. Connectivism is a learning theory that is considered to be strengthened by existing technology-based tools and is founded on the notion that ubiquitous Information Communication Technology impacts teaching and learning. The three worlds of mathematics theory support the view that the development of mathematical thinking is founded on perception, operation and reasoning. Postgraduate mathematics education students engaged in interactive workshops using different online platforms. Subsequently, a sample of participants was interviewed using a semi-structured interview schedule. The interviews were conducted via various online platforms. Data that were generated were analyzed thematically. The results revealed two main themes. These themes focused on the strengths and
\end{abstract}

challenges of using technology-based tools and resources to learn mathematics as perceived by the participants. The results of this study provide evidence that technology-based tools and resources may also be considered by lecturers when teaching mathematics topics that involve drawing complex mathematical diagrams and solving problems based on these complex mathematics diagrams. Also, the results support the view that to alleviate challenges associated with using technology-based tools and resources, lecturers need to ensure that the technology-based tools and resources being used are user-friendly, inexpensive, readily available and data-efficient. Moreover, this study support the view that lecturers need to consider attending professional development workshops and seminars that focus on integrating technology effectively in educational environments. This study has relevance globally and nationally when considering the implications of using technology-based tools and resources for learning mathematics.

Keywords Fourth Industrial Revolution, Mathematics, Microsoft Teams, MOODLE, Postgraduate Student, 
Resources, Connectivism, Technology-Based Tools, ZOOM

\section{Introduction}

We are in the era of the Fourth Industrial Revolution; globally the use of technology-based tools, devices and resources in educational contexts is extensive [23]. The Fourth Industrial Revolution (4IR) involves using innovative pedagogy in which technology-based tools and devices are rooted in society [25]. Technology-based tools, devices and resources are advancing swiftly and may soon displace traditional pedagogy in many educational contexts. The use of the Internet and Information and Communication Technology (ICT) is rapidly transforming educational contexts [10]. The use of computers and laptops within higher education contexts is common [14], with lecturers often endorsing that their students bring their laptops into their lecture rooms [13]. Within the context of this study, technology-based tools and resources include internet-based platforms and resources that may be used with computers or mobile devices which work with text, videos, audio and pictures to support teaching and learning [20]. However, within the era of the 4IR, we need to establish students' perceptions of using technology-based tools and devices for learning. This article reports on a study that sought to respond to the question: What are postgraduate mathematics education students' perceptions of using technology-based tools and resources for learning mathematics within the domains of connectivism and the three worlds of mathematics?

\section{Literature Review}

\subsection{Using Technology-based Tools and Resources for Learning Mathematics}

The use of technology by society in all spheres of life has transformed the way people think, network, and completes their activities [7]. For the teaching and learning of mathematics, Pope and Mayorga [22] assert that many internet-based websites and platforms include educational applications that may guide students' mathematics learning and achievement. The favorable effects of using technology-based tools and resources in mathematics education have been supported by other researchers [16, 21]. Also, for the teaching and learning of mathematics, technology-based tools and resources can provide access to various problem-solving approaches compared to traditional teaching and learning approaches [33].

Within the 4IR, globally, education institutions incline towards using technology-based tools for teaching and learning. Nevertheless, technology-based teaching and learning pedagogy is going to be used. In that case, lecturers' knowledge for using technology-based pedagogy is essential to ensure that technology-based tools are used effectively [24]. Also, mathematics teacher education within the era of the 4IR requires that lecturers are prepared to include technology-based tools and resources efficiently within their educational contexts [18].

Thus, within the context of using technology-based tools and resources for mathematics education, the lecturer needs to select suitable technology-based tools and resources to support students' learning. Hence, designing technology-based lectures needs to be in harmony with the technology-based tools and resources established to provide maximum support for students' understanding of mathematics [9].

Moreover, Cheung and Slavin's [6] research has shown that using technology-based tools and resources for learning mathematics has advanced students' performance. Technology-based tools and resources in mathematics educational contexts may support struggling students and those who thrive when learning mathematics [4]. Although technology contributes to advancements in society, many students are still not competent users of technology [3] or do not have access to the necessary technology-based devices required to participate in online teaching and learning. In a developing country like South Africa, students' access to technology-based devices is diverse. Challenges persist as students need to continually learn new skills in a technologically advanced society [19]. Thus, education structures need to be adapted to prepare students to flourish in these environments [5, 32]. In the study under focus, technology-based tools and resources were used to teach and learn mathematics within a higher education context.

\subsection{Exploring Connectivism as a Theoretical Lens}

Connectivism is a learning theory suggested by Siemens in 2004 and is applicable in the current technological era [8]. Siemens [26] maintains that connectivism as a learning theory is reinforced by existing technology-based tools and is founded on the notion that ubiquitous Information Communication Technology (ICT) influences a student's life, communication and learning methods. Along similar lines, in many educational contexts, technology has been seen as necessary for the development of teaching and learning [33]. Recently, technology has transformed teaching and learning so much that technology-based pedagogy can advance teaching and learning success by offering applicable collaborations among students, peers, and the lecturer [31]. While technology-based tools and resources can promote teaching and learning success, within the domains of connectivism, technology-based devices and resources must be readily available to all students since accessibility has significant implications for 
student collaboration and achievement [12].

Connectivism can be regarded as a learning theory next to behaviorism, constructivism and cognitivism [8]. Siemens [26] maintains that connectivism can be considered a reorganized form of constructivism suitable for the technological era. Connectivism can be described as a network system of information that emphasizes technology-based tools and resources to improve and prolong online communication [8]. The positive effect of integrating technology-based tools within educational contexts has been instrumental in stimulating mathematics learners to develop higher-order thinking skills [17]. Also, the supportive effect of integrating technology-based tools on teaching and learning can provide students with the ability to use diverse methods to accomplish their tasks with ease independently [1].

Apart from supporting students with collaboration and communicating knowledge, connectivism also helps students solve and complete activities [8]. Linking students with technology-based tools and resources online does not necessarily occur in a specific educational environment; this is pervasive due to our Internet access ${ }^{1}[2]$. Thus, connectivism offers the lecturer a model representing teaching and learning aspects that cannot be perceived or experienced directly [11]. Connectivism denotes that the information and understanding develop in a system from the collaborations within a group [8]. Thus, collaboration is supported within the domains of connectivism, and this theory also offers students the opportunity for individual learning [15].

In this study, the integration of technology-based tools and resources enhanced postgraduate mathematics education students' understanding of models of assessments, the designing of performance assessments tasks for mathematics and the solving of mathematics problems. The notions of connectivism were apparent in this study as students interacted online to complete each workshop task. Thus, the tasks were completed after students engaged in online collaborations with their peers and the lecturer. In this study, the theory of connectivism was also instrumental in illustrating how the postgraduate mathematics education (ME) students adapted themselves to the transformed technology-based educational environment; it was evident that the participants of this study made new links with existing and new knowledge [8]. Subsequently, after actively participating in the two interactive technology-based workshops, the postgraduate ME students were invited to participate in technology-based semi-structured individual interviews. The interviews aimed to identify the postgraduate ME students' perceptions of using technology-based tools and resources for learning mathematics within the domains of

1 The Internet is a global system of interconnected computer networks that consists of private, public, academic, business, and government networks linked by electronic, wireless, and optical networking technologies. connectivism. The links between new and existing knowledge made by postgraduate ME were discussed further during the interviews with participants.

\subsection{Exploring the Theory of the Three Worlds of Mathematics}

As individuals develop from young children to adults, their mathematic thinking develops from perception and recognition to repetition; they use language and reasoning to ensure a complete scope of mathematical thinking [28]. Tall [27] refers to these ideas about mathematical thinking and development as the three worlds of mathematics. The three worlds of mathematics suggest that mathematical thinking develops as students understand and form mathematical concepts. This implies that not all mathematical notions are created in the same manner, meaning that teaching different mathematical concepts need to follow different approaches. According to Tall [29], the three worlds of mathematics include perception or conceptualization, operational or symbolic calculations and formalization or axiomatic reasoning of ideas. While teachers may use real-world situations, artefacts, and manipulatives to teach specific mathematics concepts, the teaching of other mathematical concepts may require a different type of pedagogy.

In this study, the notions of the three worlds of mathematics were apparent as students were provided with an opportunity to think about their perceptions of the models of mathematical assessments and performance-based tasks first before they could decide on how best to use operations, symbols and manipulations to solve the real-world problems. Thereafter, the participants collaborated online to discuss and provide their verbal reasoning for their solutions and strategies as they completed each workshop task. Thus, the tasks were completed after students engaged in online collaborations with their peers and the lecturer. In this study, the theory of the three worlds of mathematics helped demonstrate how the postgraduate mathematics education (ME) students adapted themselves to the transformed technology-based educational environment; it was evident that the participants of this study made new links with existing and new knowledge [8]. These links were founded on the notions of the three worlds of mathematics.

After actively participating in the two interactive technology-based workshops, the participants were invited to participate in technology-based semi-structured individual interviews. The interviews aimed to identify the postgraduate ME students' perceptions of using technology-based tools and resources for learning mathematics while acknowledging their use of the ideas of the three worlds of mathematics. Participants' perceptions and conceptualization of mathematical ideas, their links made between new and existing knowledge and the use of various mathematics procedures and problem-solving 
strategies were interrogated and discussed further during the interviews.

\section{Materials and Methods}

\subsection{General Background}

This qualitative and interpretive study was conducted in one Teacher Education institution in the 2019 academic year. This Teacher Education institution is located in KwaZulu-Natal, South Africa. The ethics committee of participating institution approved gatekeeper access and ethical clearance. Each participant was provided with an informed consent sheet that described the purpose and process of the study. This information sheet also included the participants' right to withdraw from the research without prejudice at any time. The study included two interactive technology-based workshops and one semi-structured individual technology-based interview with postgraduate mathematics education students. Also, the participants provided consent for the recording of the technology-based workshops and interviews. Furthermore, the participants' anonymity was assured by using codes instead of the participants' actual names.

\subsection{Participants}

Thirty nine postgraduate mathematics education students were invited to participate in the study. An informed consent form was provided for all participants. The study sample was twenty-three postgraduate mathematics education (ME) students who responded positively to the invitation to participate in the study (14 male and nine female). Five participants were chosen at random for the pilot study, and eighteen ME students participated in the main study.

\subsection{Research Instruments and Research Process}

\subsubsection{Technology-based Interactive Workshops}

Two interactive technology-based workshops were conducted with the postgraduate ME students in the 2019 academic year. The researchers facilitated these interactive technology-based workshops, and participants were provided with hard copies of additional notes, case studies, and examples of assessments focusing on the content under study. The researchers shared other resources with the ME students using Moodle $^{2}$. The interactive technology-based workshops were conducted online. The first workshop was conducted using the Microsoft Teams $^{3}$ platform, and the second workshop

\footnotetext{
2 Moodle is an official online learning management system used at the participating university. It is an online learning platform.

3 Microsoft Teams is an online platform developed by Microsoft. This online platform is used officially by the participating university for meetings, chats, communication and videoconferencing for students and
}

was conducted using the Zoom ${ }^{4}$ platform. The first workshop focused on assessment models for mathematics, and the second workshop focused on designing performance assessment tasks for mathematics. At the end of the second interactive technology-based workshop, the participating ME students were invited to semi-structured individual interviews. Each participant was given the option of selecting the date and time for their interview. Each participant could also indicate which online platform they wished to be interviewed on (WhatsApp ${ }^{5}$ Video platform, Zoom platform, Microsoft Team platform, Skype $^{6}$ calls, or Viber ${ }^{7}$ calls)

\subsubsection{Technology-based Semi-Structured Individual Interviews}

The semi-structured interview aimed to probe postgraduate mathematics education (ME) students' perceptions of using technology-based tools and resources for learning within the domains of connectivism. Each interview lasted for nearly 30 minutes. The interviews were conducted using technology-based platforms, for example, WhatsApp Video calls, Zoom meetings, Microsoft Team meetings, Skype calls, and Viber calls. Each interview began with a few social questions to make each participant more comfortable and at ease with the interview process.

The interview then progressed to specific questions revolving around the postgraduate ME students' perceptions of using technology-based tools and resources for mathematics learning within the domains of connectivism. The interviews were semi-structured and were established on one central question: What are postgraduate mathematics education students' perceptions of using technology-based tools and resources for learning mathematics within the domains of connectivism and the three worlds of mathematics?

The technology-based interviews were recorded and then transcribed. Subsequently, transcriptions of each interview were emailed to each of the ten postgraduate $\mathrm{ME}$ students who were interviewed so that each participant could peruse their individual interview for accuracy.

\subsection{Pilot Study}

A pilot study was conducted with five randomly selected

lecturers.

4 Zoom is a video conferencing software application (app). This app allows individuals to communicate virtually with friends, colleagues, peers and family. Zoom is an official online teaching and learning platform used at the participating teacher education institution.

5 WhatsApp is a free messenger application that uses the internet to send and receive messages and calls. WhatsApp is used unofficially at the participating university by lecturers and students as an online platform for communication.

6 Skype is an online telecommunication platform used officially at the participating university. It is used for making free online calls and sending free online messages between students and lecturers.

7 Viber is a free messenger application and uses the internet to send and receive messages and calls. Viber is used unofficially at the participating university by lecturers and students as an online platform for communication. 
postgraduate ME students to ensure the dependability of the research process and the research instruments. Through the pilot study, the research instruments were revised to a minor extent. For example, during the pilot study, it was observed that there were some minor technical errors noted in the workshop observation schedule and the workshop observation schedule required additional items to assist in generating in-depth data. Also, some questions on the semi-structured interview schedule were ambiguous. Subsequently, all research instruments were revised, and the language used during the semi-structured interviews was unambiguous and straight forward to increase the interviews' trustworthiness.

\subsection{Main Study}

Eighteen postgraduate ME students participated in the main study. Data were generated by using two interactive technology-based workshops and one semi-structured technology-based interview. Although $18 \mathrm{ME}$ students agreed to participate in all phases of the main study, due to personal reasons, $18 \mathrm{ME}$ students participated in the first phase (interactive technology-based workshop one) and fifteen of the $18 \mathrm{ME}$ students participated in the second phase (interactive technology-based workshop two). For the third phase (semi-structured individual technology-based interviews), 10 of the $18 \mathrm{ME}$ students agreed to be interviewed.

To ensure the dependability of the generated data analysis, only data generated from the $10 \mathrm{ME}$ students who participated in all three phases of the research process were analyzed. This analyzed data has been included in the results and the discussion of the results section for this article. Six male and four female ME students participated in all three phases of the research process of the main study. To assure participants of their confidentiality and anonymity, codes were used.

The postgraduate mathematics education (ME) students were initially coded randomly using a number from 1-18 since $18 \mathrm{ME}$ students agreed to participate in the main study. Subsequently, not all $18 \mathrm{ME}$ students participated in the second interactive technology-based workshop or the semi-structured individual technology-based interview. The participants who participated in the semi-structured individual technology-based interview were ME student 1, ME student 3, ME student 4, ME student 8, ME student 9, ME student 11, ME student 12, ME student 14, ME student 16 and ME student 17.

\subsection{Data Analysis}

The data analysis process assisted in identifying key themes from the data generated. A step-by-step process was used to analyze the generated data. Firstly, both technology-based interactive workshop recordings were analyzed to ascertain the participants' responses to questions posed during the two workshops. Key findings based on this analysis were coded using key terms or concepts that linked the ME student's answers. Secondly, the semi-structured individual interview transcripts were carefully read, and notes were made. Each interview was then examined and analyzed to explore what the information meant within the study context.

Subsequently, a list of standard codes was identified based on the analysis of all generated data for the two workshops and the individual semi-structured interviews. Similar codes were grouped. These codes were carefully reviewed and organized as themes; thus, thematic coding was inductively used to generate themes. The arrangement of themes also merged notions established on the ideas of connectivism and the three worlds of mathematics. Two main themes were identified from the qualitative data analysis of the two interactive workshops and semi-structured interview transcripts. These themes that were identified are presented in the results section that follows.

\section{Results}

\subsection{Strengths of Using the Technology-Based Tools and Resources for Learning Mathematics}

The participants who participated in all three phases of this research study indicated strengths in using technology-based tools and mathematics learning resources. Selected responses from the semi-structured interviews are presented as follows.

\subsubsection{Creates a Supportive Connected Mathematics Learning Environment}

The participants indicated that using technology-based tools and resources helped create more support than they would have received in a traditional teaching and learning educational context. The use of technology provided more ways of communicating and connecting with each other. These sentiments are reflected in selected excerpts taken from the semi-structured interview transcripts that follow.

ME student 1: ... it helps to have the group connected using technology....we can discuss our issues freely at any time...

ME student 4: ...I feel that I can get support from other students and the lecturer by using technology...I don't have to wait for class time if I have problems understanding the maths...

ME student 12: .... we all help each other at any time... it is better than our usual in-class lecture... it is a better way to stay connected with each other...

ME student 17: ... we assist each other if we do not understand certain parts of the assessment in the maths section...it is easier to help each other since we have so many ways to use technology to help each other...we can use WhatsApp which is easy to use to help each other... 
As was evident from the preceding interview transcripts, the participants valued using technology-based tools and resources. The participants believed that technology provided more ways of offering and communicating support and assistance to each other if they had challenges with the mathematics being taught. The use of technology-based tools allowed the participants to discuss their perceptions and reasoning within the supportive online community as they solved the workshop tasks.

\subsubsection{Saves Time during the Teaching and Learning of Mathematics}

The participants indicated that the use of technology-based tools and resources helped save time during mathematics learning. More time was saved in developing tasks, assessments and drawing complex mathematics diagrams than they would have saved in a traditional teaching and learning educational context. The use of technology also gave more time and make it efficient to solve mathematics tasks and adding to students' existing knowledge base. These sentiments are reflected in excerpts from the semi-structured interview transcripts as follows.

ME student 8: ... when we use technology, it saves times, and it is quick to respond to the group...it provides us with knowledge all the time...

ME student 9: ...we can come up with online assessments quickly. It is quick to develop assessments for any grade using technology....we can add to our knowledge because of technology...

ME student 14: ... we don't have to wait for the lecture...we can discuss our queries quickly using technology...we can come up with solutions to the maths problems quicker by using technology...

ME student 16: ... it is easy and quick to use software to draw complex maths diagrams on the computer...it saves time than if we had to draw these complex diagrams by hand...

ME student 17: ... we can discuss so many more maths concepts in a short space of time by using technology... it saves lots of time in our discussions and practicing the maths problems... we cover more work in a shorter amount of time...

As was evident from the preceding interview transcripts, the participants appreciated using technology-based tools and resources. The participants thought that technology saved learning time concerning solving tasks, developing assessments and drawing complex diagrams for mathematics. The use of technology-based tools supported the participants with adding to their knowledge base as they collaborated online on their use of mathematical procedures and operations for problem-solving.

\subsection{Challenges of Using Technology-based Tools and Resources for Learning Mathematics}

The participants who participated in all three phases of this research study indicated that there were also challenges to using technology-based tools and mathematics learning resources. Their responses during the semi-structured interviews are presented as follows.

\subsubsection{Creates Distractions within the Mathematics Learning Environment}

The participants indicated that the use of technology-based tools and resources created distractions while they were learning mathematics. Often while students were busy learning mathematics, they lost focus due to unimportant messages their peers placed on WhatsApp chats and Moodle. Also, having access to the Internet during lecture time resulted in students' searching the Internet for information not related to mathematics. These sentiments are reflected in the selected excerpts taken from the semi-structured interview transcripts as follows.

ME student 1: ... sometimes you are busy doing a maths task and then you receive WhatsApp messages from the group...the message may not deal with maths, and I lose focus on what I am doing...

ME student 3: ... although technology is useful for learning maths it also distracts and interrupts us...some students send messages late on Moodle....and we then need to read it because we think it is something important for lectures...only to find it is not important for us...this disturbs me at night...

ME student 8: ...the many messages we receive from the group is sometimes a nuisance, especially when it is social messages...this takes time away from learning maths..

ME student 14: ... sometimes we are also discussing on Skype important maths problems and solutions. Then someone starts talking about something else that is not related to maths...this distracts the class, and we waste time instead of learning maths...the lecturer stops this, but some students forget that this space is only for discussing maths...

ME student 17: ...technology creates lots of disruptions...sometimes we are searching for information on the Internet, and then we see something else, and we use class time to explore other stuff...this disturbs our thinking...

As was evident from the preceding interview transcripts, the participants believed that using technology during lecture time and while learning mathematics created disruptions to their mathematics learning. The participants felt that technology allowed their peers to place social messages and other information that did not relate to mathematics on different online platforms. These messages led to distractions while learning mathematics.

\subsubsection{Requires Compulsory Access to Expensive Devices and Data}

The participants indicated that using technology-based 
tools and resources for learning mathematics required access to technology-based devices and data access. Having access to the Internet and computers while they were at campus posed no challenge; however, when they needed to used technology-based tools and resources at home, not all participants had this compulsory access to data and devices. Access to computers and data for using technology-based tools and resources was challenging and expensive. These sentiments are reflected in the excerpts taken from the semi-structured interview transcripts as follows.ME student 3: ... using technology is helpful for learning maths...too many devices are required to learning using technology...

ME student 4: ...before all I needed was a pen and some paper to learn maths...now I need a computer...I also need to be able to go on the Internet...

ME student 9: ....when we are on campus, we can use technology ... at night when I am home I don't have good connectivity... Internet is slow and not always reliable...

ME student 12: ...I don't have a computer at home...I use my phone...I have to use data on my phone...very costly...

ME student 16: ....we share a phone at home...the phone is important for lectures when we have online workshops...sometimes I don't see all my messages on my cell phone...it is not with me all the time...I also have to buy more airtime to get more data...very expensive for me...

As was evident from the preceding interview transcripts, the participants believed that using technology for lectures required access to expensive devices and data. The participants thought that using technology at the campus was easy since they had access to computers and free access to the Internet. However, when they were at home, this became a challenge. Not all the participants had easy access to devices when they were at home. The participants also indicated that having access to the Internet and data for online resources and online platforms was expensive.

\section{Discussion of Results}

The qualitative results provide evidence of postgraduate mathematics education (ME) students' perceptions of using technology-based tools and resources for learning mathematics. The participants generally indicated strengths and challenges to using technology-based tools and resources for learning mathematics. Firstly, the participants valued the supportive connected mathematics learning environment created by using technology. The notions of connectivism support these perceptions. The theory of connectivism maintains that students enhance their understanding of information by connecting and collaborating within a group using technology [8]. The participants appreciated the online-based support they were receiving from their peers and the lecturers. This collaboration supported the participants when using operations for solving problems in mathematics. They were provided with the opportunity to discuss their reasoning for their mathematical procedures and operations, which helped them develop their mathematical thinking [29]. This type of technology-based collaboration helped the participants clarify queries they had with the mathematics sections under discussion, which supported their mathematical thinking [27]. Similarly, Kizito [15] proposes that collaboration is reinforced within the ambits of connectivism, and the theory of connectivism also provides students with the opportunity for individual learning. Moreover, the theory of the three worlds of mathematics allows students to conceptualize mathematical ideas independently before moving on to verbally explain their choice in procedures and mathematical operations [28]. Thus, the participants embraced connectivism and the theory of the three worlds of mathematics by collaborating and supporting their peers through technology.

Secondly, the participants perceived that using technology-based tools and resources for learning mathematics helped them save time when working on mathematics tasks. This perception is supported by research [7], which maintains that Information and Communication Technology (ICT) saves times on tasks and activities. Moreover, within the domains of connectivism, the adaptable nature of technology-based tools for teaching and learning can provide students with the opportunity to use diverse techniques to complete their tasks timeously with ease [1]. The participants also mentioned that using technology-based tools and devices for learning mathematics helped them add to their existing knowledge base. This perception is supported within the realms of connectivism and the theory of the three worlds of mathematics, in that connectivism helps students with linking new knowledge with existing knowledge to enhance understanding [8]. The three worlds of mathematics provide students with the ability to provide formal reasoning to connect new knowledge with existing knowledge to develop mathematical thinking further [29]. Thus, the participants embraced the notions of connectivism and the three worlds of mathematics by using technology-based tools and resources in collaboration with their connected network of peers and lecturers to enhance their existing knowledge base.

Thirdly, the participants perceived that using technology-based tools and resources for learning mathematics created distractions within the mathematics learning environment. This perception is supported by research [13], which maintains that technology-based tools and devices distract students. They tend to engage in non-academic related work when they have access to the Internet and technology-based devices. Finally, the participants perceived that they needed to access expensive technology-based devices when using technology-based 
tools and devices while learning mathematics. They needed to purchase data to use the Internet. The participants mentioned that the purchasing of data to use the Internet was expensive. Similarly, research [14] maintains that although technology-based devices are widely used in educational contexts, they are costly to purchase. Notions of connectivism also hold that students' access to expensive devices, the Internet, and data are essential since access to these crucial resources has significant implications for technology-based collaboration and achievement [12].

\section{Conclusions and Recommendations}

This study aimed to explore postgraduate mathematics education students' perceptions of using technology-based tools and mathematics resources. This study provides evidence that participants experienced strengths and challenges in using technology-based tools and resources for learning mathematics. The participants also provided evidence indicating they valued the supportive online environment created and supported by connectivism. Within the ambits of connectivism and the three worlds of mathematics theory, participants were supported as they perceived and conceptualized mathematical information to use the appropriate mathematical operation to ensure effective problem-solving. Through this effective step-by-step problem-solving and development in mathematical thinking, the participants succinctly articulated reasons for their mathematical thinking to other participants within their online educational environment. Thus, if the ideas of connectivism and the three worlds of mathematics are embraced within technology-based mathematics educational contexts, the use of technology-based tools and resources may strengthen students' mathematical learning.

Also, the nature of collaboration within the Fourth Industrial Revolution era has changed, and the notions of connectivism transform technology-based educational contexts. Based on this study, characteristics of connectivism and the three worlds of mathematical thinking validate collaborative and connected approaches that are generally effective in alleviating mathematics anxiety and realizing successful mathematics learning outcomes. This was evident in this study since the researchers within this study transformed traditional pedagogy to create a collaborative and interactive technology-based educational context. The students were provided with the opportunity to conceptualize mathematical ideas and use different operations to solve mathematics problems. As the workshops progressed, the participants actively validated their mathematics solutions by offering reasons for their problem-solving strategies. This change to a collaborative and interactive technology-based educational context enhanced students' mathematical thinking and mathematics learning. Participants in this study encompassed the ideas of connectivism and added to their existing knowledge base by using technology-based tools and resources. As the participants developed their mathematical thinking by encompassing the notions of the three worlds of mathematics, they interacted collaboratively by using technology-based tools and resources to support each other and create a connected mathematics learning environment.

This article concludes with some recommendations for lecturers who wish to use technology-based tools and resources to learn mathematics. Firstly, the advantages of using technology-based tools and resources for mathematics learning are essential to note. Lecturers ought to acknowledge that using technology-based tools and resources within the mathematics educational environment creates a supportive and connected mathematics learning environment. Also, the use of technology-based tools and resources assists in saving time when learning mathematics. Lecturers may consider using technology for the learning of mathematics when collaboration, group-work and interaction are essential to achieve the learning outcomes of the mathematics topic under discussion. Technology-based tools and devices may also be considered by lecturers when teaching mathematics topics that involve drawing complex mathematical diagrams and solving problems based on these complex mathematics diagrams.

Secondly, the challenges of using technology-based tools and resources for mathematics learning are essential for lecturers to acknowledge. To alleviate these challenges, lecturers need to ensure that the technology-based tools and resources being used are user-friendly, inexpensive, readily available and data-efficient. Also, lecturers need to ensure that distractions caused by using technology-based tools and resources are kept to a minimum. One way of meeting this challenge is to enforce strict rules on students when they are provided with the opportunity to use technology to support their mathematics learning.

Finally, based on this study it was evident that for the successful use of technology-based tools and resources in the mathematics educational environment, lecturers need to use appropriate technology-based tools and resources to achieve maximum learning outcomes. Lecturers could consider attending professional development workshops and seminars that focus on integrating technology in educational environments. These recommendations would benefit lecturers globally, as we consider using technology-based tools and resources to enhance mathematics learning.

\section{Acknowledgments}

The authors are appreciative of the National Research Foundation (NRF) who partially funded this research. 


\section{REFERENCES}

[1] F.K. Ahmad. Use of assistive technology in inclusive education, Transcience, Vol.6, No.2, 62-77, 2015. https://www.academia.edu/40022315/Use_of_Assistive_Tec hnology_in_Inclusive_Education_Making_Room_for_Diver se_Learning_Needs

[2] F. Bell. Connectivism: A network theory for teaching and learning in a connected world, The University of Salford, Vol.1, No.1, 1-7, 2009

[3] S. Bennett, K. Maton, L. Kervin. The 'digital natives' debate: A critical review of the evidence, British Journal of Educational Technology, Vol.39, No.5, 775-786, 2008.

[4] C.D. Bruce. Technology in the mathematics classroom: Harnessing the learning potential of interactive whiteboards, What works? Research into Practice, Vol.38, No.1, 1-4, 2012.

[5] J. Butler-Adam. The Fourth Industrial Revolution and education, South African Journal of Science, Vol.114, No.5, 1, 2018. https://doi.org/10.17159/

[6] A.C.K. Cheung, R.E. Slavin. The effectiveness of educational technology applications for enhancing mathematics achievement in K-12 classrooms: A meta-analysis, Educational Research Review, Vol.9, No.1, 88-113, 2013. https://doi.org/10.1016/j.edurev.2013.01.001

[7] W. de Wet, E. Koekemoer, J.A. Nel, Exploring the impact of information and communication technology on employees' work and personal lives, South African Journal of Industrial Psychology, Vol.42, No.1, 1-11, 2016. https://doi.org/10.41 02/sajip.v42i1.1330

[8] S. Downes. Recent work in connectivism, European Journal of Open, Distance and e-Learning, Vol.22, No.9, 113-132, 2019. https://doi.org/10.2478/eurodl-2019-0014

[9] P. Drijvers. Digital technology in mathematics education: Why it works (or doesn't). PNA, Vol.8, No.1, 1-20, 2013. https://doi.org/10.1007/978-3-319-17187-6_8

[10] A. Du Plessis. Editorial. Information and communication technologies and educational change, Educational Research for Social Change (ERSC), Vol.2, No.1, 1-6, 2013.

[11]B. Duke, G. Harper, M. Johnson. Connectivism as a digital age learning theory, 2013. Online available from https://www.hetl.org/wp-content/uploads/2013/09/HETLRe view2013SpecialIssueArticle1.pdf

[12]B. Gilbert. Online learning revealing the benefits and challenges. (M.S. Special Education), St. John Fisher College, Rochester, New York, 2015.https://fisherpub.sjfc.e du/education_ETD_masters/303/

[13] G. Janchenko, A. Rodi, M.J. Donohoe. Impact of computers in the classroom environment-A distraction or an essential tool? Issues in Information Systems, Vol.19, No.4, 10-15, 2018. https://doi.org/10.48009/4_iis_2018_10-15

[14] R.H. Kay, S. Lauricella. Exploring the benefits and challenges of using laptop computers in higher education

classrooms: A formative analysis, Canadian Journal of Learning and Technology, Vol.37, No.1, 1-18, 2011. https://files.eric.ed.gov/fulltext/EJ930740.pdf

[15]R.N. Kizito. Connectivism in learning activity design: Implications for pedagogically-based technology adoption in African Higher Education contexts, International Review of Research in Open and Distributed Learning, Vol.17, No.2, 19-39, 2016.

[16] N. Mlotshwa, A. Chigona. Using Moodle to enhance Mathematics learning in Grade 10 classrooms in South Africa. Paper presented at the E-Learn 2018 Conference, Las Vegas. The United States of America, 2018. http://digitalknowledge.cput.ac.za/bitstream/11189/6936/1/ Mlotshwa_N_Chigona_A_Edu_2018.pdf

[17]D. Murphy. A literature review: The effect of implementing technology in a high school mathematics classroom, International Journal of Research in Education and Science (IJRES), Vol.2, No.2, 295-299, 2016.

[18] J. Naidoo, A. Singh-Pillay. 2020. Exploring mathematics teachers' professional development: Embracing the Fourth Industrial Revolution, Universal Journal of Educational Research, Vol.8, No.6, 2501-2508, 2020. https://doi.org/10. 13189/ujer.2020.080634

[19] D. Ng'ambi, C. Brown, V. Bozalek, D. Gachago, D. Wood. Technology-enhanced teaching and learning in South African higher education-A rearview of a 20 -year journey, British Journal of Educational Technology, Vol.47, No.5, 843-858, 2016.

[20]N. Peachey. Digital tools for teachers, PeacheyPublications.Com, Kent, United Kingdom, 2017.

[21]P.E. Persson. Teaching and learning mathematics at secondary level with TI-Nspire technology, 2011. Online available fromhttps://www.diva-portal.org/smash/get/diva2: 1410497/FULLTEXT01.pdf

[22] S. Pope, P. Mayorga. Enriching Mathematics in the Primary Curriculum Exploring the Primary Curriculum. Sage, London, United Kingdom, 2019.

[23] J.S. Pyper. Learning about ourselves: A review of the mathematics teacher in the digital era, Canadian Journal of Science, Mathematics and Technology Education, Vol.17, No.3, 234-242, 2017. https://doi.org/10.1080/14926156.201 7.1297509

[24] L. Qing. Would we teach without technology? A professor's experience of teaching mathematics education incorporating the Internet, Educational Research, Vol.45, No.1, 61-77, 2003.

[25] K. Schwab. The Fourth Industrial Revolution: What it means, how to respond, 2016. Online available from https://www.weforum.org/agenda/2016/01/the-fourth-indust rial-revolution-what-it-means-andhow-to-respond

[26] G. Siemens. Connectivism: A learning theory for the digital age, International Journal of Technology and Distance Learning, Vol.1, No.1, 1-9, 2005. http://www.itdl.org/Journ al/Jan 05/article01.htm

[27] D. Tall. The three worlds of mathematics, For the Learning of Mathematics, Vol.23, No.3, 29-33, 2004. http://homepages. warwick.ac.uk/staff/David.Tall/pdfs/dot2004a-3worlds-flm. pdf 
[28]D.Tall. A theory of mathematical growth through embodiment, symbolism and proof, Annales de Didactique et de Sciences Cognitives, Irem de Strasbourg, Vol.11, No.1, 195-215, 2006. https://homepages.warwick.ac.uk/staff/Davi d.Tall/pdfs/dot2006e-theory-math-growth-annales.pdf

[29] D.Tall. The transition to formal thinking in mathematics, Mathematics Education Research Journal, Vol.20, No.2, 5-24, 2008. https://files.eric.ed.gov/fulltext/EJ820231.pdf

[30] O. Umugiraneza, S. Bansilal, D. North. Exploring teachers' use of technology in teaching and learning mathematics in KwaZulu-Natal schools, Pythagoras, Vol.39, No.1, 1-6, 2018. https://doi.org/10.4102/pythagoras.v39i1.342
[31] P. Vululleh. Determinants of students' e-learning acceptance in developing countries: An approach based on Structural Equation Modeling (SEM), International Journal of Education and Development using ICT, Vol.14, No.1, 141-151, 2018. https://www.learntechlib.org/p/183560/

[32] E. Wahyuni. Improving students' independence and collaboration with blended learning, Advances in Social Science, Education and Humanities Research, Vol.231, No.1, 613-616, 2018. http://ftp.jrc.es/EURdoc/JRC66836

[33] S. Yang, D. Kwok. A study of students' attitudes towards using ICT in a social constructivist environment, Australasian Journal of Educational Technology, Vol.33, No.5, 50-62, 2017. https://doi.org/10.14742/ajet.2890 